\title{
Avaliação psicológica de crianças surdas pelo Teste das Pirâmides Coloridas de Pfister
}

\author{
Lucila Moraes Cardoso - Universidade São Francisco \\ Cláudio Garcia Capitão - Universidade São Francisco ${ }^{1}$
}

\begin{abstract}
Resumo
A técnica projetiva das Pirâmides Coloridas permite conhecer aspectos da personalidade de quem é examinado e ser útil na avaliação de crianças com dificuldades de comunicação, tais como os surdos. Este estudo objetivou verificar evidências de validade da técnica de Pfister no contexto da surdez e analisar possíveis influências dos modelos educacionais nas crianças surdas. Participaram 37 ouvintes e 81 surdos, sendo 31 oralizados, 29 bilíngües e 21 comunicação total. Os grupos foram compostos por crianças de 6 a 12 anos, de ambos os sexos e escolaridade do pré à sexta série do ensino fundamental. Na comparação dos grupos, surdos e ouvintes, verificou-se prevalência da cor violeta em crianças surdas. Já entre os grupos de surdos houve diferença significativa na presença de alguns indicadores de organização cognitiva. Este estudo, contudo, corrobora as evidências de validade para o uso do teste de Pfister com crianças surdas.

Palavras-chave: Teste das Pirâmides Coloridas de Pfister; Avaliação psicológica; Crianças surdas.
\end{abstract}

\section{Evaluation of deaf children by the Colored Pyramids Test of Pfister}

\begin{abstract}
The projective technique of the Colored Pyramids allows to know personality aspects from whom is been examined and can be useful for children's evaluation with communication difficulties, such as the deaf. This study had the goal of verifying technique evidences of validity Pfister to the deafness context and it intends to analyze possible influences of the educational models in the deaf children. 37 listeners and 81 deaf took part in this study, being 31 who use oral language, 29 bilingual and 21 total communication. The groups were composed by children from 6 to 12 years, both sexes and education students from elementary to sixth-grade classes. Comparing the groups, deaf and listeners, it was verified a larger prevalence of the violet color in deaf children. But among groups of deaf there was significant difference in the presence of some indicators of cognitive organization. This study, however, corroborates with the validity evidences for the use of the test Pfister with deaf children.

Keywords: Colored Pyramids Test of Pfister; Psychological evaluation; Deaf children.
\end{abstract}

\section{Introdução}

A maioria das pesquisas sobre surdez, nas últimas décadas, foi realizada por lingüistas e fonoaudiólogos, que tomaram as rédeas das discussões. A maioria desses estudos, como pode ser observado nos artigos dos mais de 150 anos de publicação da revista American Annal of Deaf, preocupavase com estratégias e métodos de comunicação e educação, treinamento de professores, desenvolvimento da linguagem e relacionamento das crianças surdas com seus familiares e profissionais (American Annal of Deaf, 2006).

O termo surdez se refere à audição socialmente incapacitante no que tange a desenvolver a linguagem oral, pois os ruídos não possuem um significado. Assim, surdas são pessoas com significativa perda auditiva, seja ela total ou parcial (Lopes Filho, 1997). A surdez é considerada uma das deficiências que exige maior esforço na reabilitação e causa maior incerteza quanto ao desenvolvimento cognitivo e lingüístico da criança (Torres, 2005). Portanto, deve ser considerada em vários aspectos, entre eles médico, sociológico, psicológico e educacional (Bailly, Dechoulydelenclave \& Lauwerier, 2003; Hindley, 1997).

A falta de uma linguagem na primeira infância traz graves conseqüências para o desenvolvimento social, emocional e intelectual. Poucos dos que perderam a audição precocemente conseguem falar, e os que conseguem dificilmente possuem uma fala inteligível. A incompreensão dos ouvintes muitas vezes faz com que os surdos se sintam inibidos e desencorajados (Capovilla, 1997; Capovilla \& Raphael, 2004; Sole, 2003; Torres, 2005; Vygotsky, 1989).

É freqüente o desconhecimento da família sobre as implicações da surdez. Muitas vezes, os familiares acreditam que os surdos são incapazes e terão grandes

\footnotetext{
${ }^{1}$ Endereço para correspondência:

Universidade São Francisco - Programa de Pós-Graduação Stricto Sensu em Psicologia

Avenida Alexandre Rodrigues Barbosa, 45 - Centro - 13251-90 - Itatiba-SP

E-mail: claudio.capitao@saofrancisco.edu.br
} 
dificuldades para se desenvolver de modo adequado. As famílias pressupõem que o ser surdo implicará fracasso escolar, acadêmico, profissional e social (Harrison, Lodi \& Moura, 1997).

Os pais ou responsáveis por crianças surdas deverão escolher um modelo educacional para a criança. Destaca-se que essa decisão não se restringe a um tratamento ou alternativa educacional e sim a uma opção de vida, pois esse modelo influenciará em muitos fatores da vida do surdo, entre eles na forma de comunicação e no seu reconhecimento como deficiente (visão médica) ou diferente (visão culturalista). Quanto antes for feita a escolha entre o oralismo, bilingüismo e comunicação total melhor será para o desenvolvimento da criança (Torres, 2005).

O oralismo visa à integração do surdo com o ouvinte. Os defensores dessa vertente preconizam a oralidade como indispensável para o desenvolvimento integral das crianças (Goldfeld, 1997; Marchesi, 1995; Sá, 1999). Para tal, os surdos freqüentam a escola regular junto com os ouvintes, ampliando as possibilidades e a necessidade de uso da fala como recurso de comunicação. Essa abordagem é questionada, pois o tempo todo o ouvinte é considerado um padrão que deve ser alcançado pelos surdos "bem-sucedidos" (Ferreira Brito, 1993; Góes, 1999; Kyle, 1999; Perlin, 1998; Skliar, 1998). Além disso, poucas crianças surdas chegam a falar, e as que conseguem dificilmente têm competência para manter um diálogo.

A comunicação total, antes conhecida como bimodal, preocupa-se com a comunicação surdo-ouvinte e a comunicação surdo-surdo. Desse modo, é feito o uso de diversos recursos de comunicação, entre eles: sinais, oralização, leitura orofacial, gestos indicativos e expressivos, apontamento de objetos presentes no momento, linguagem escrita, soletração com os dedos, pantomina e desenhos (Góes, 1999; Magalhães, 2006), que são ajustados de acordo com as necessidades da criança. Verificou-se que, em relação ao oralismo, alguns aspectos educativos e de comunicação foram melhorados. Mas, poucos sujeitos alcançam autonomia na escrita como modo de produção de linguagem (Lacerda, 1998). A importância da comunicação total é que forneceu acesso aos sinais que antes eram impedidos e abriu espaço para o bilingüismo.

O bilingüismo contrapõe-se ao oralismo por priorizar a língua visogestual e à comunicação total por defender um espaço efetivo dos sinais na língua (Lacerda, 1998), isto é, preocupa-se primariamente com a comunicação surdo-surdo e depois com a comunicação surdo-ouvinte. Desse modo, a língua de sinais é considerada a língua materna do surdo (Goldfeld, 1997; Sá, 1999). Neste modelo, o Surdo (com $S$ maiúsculo) deve ser reconhecido sob a perspectiva da alteridade, em que as identidades surdas são pensadas a partir do conceito de diferença ao invés do conceito de deficiência (Perlin, 1998).

Esses modelos educacionais interferem também no tipo de escola em que a criança surda estudará. O surdo oralizado e comunicação total na maioria das vezes estuda em escola comum, onde surdos e ouvintes estudam juntos e são expostos aos mesmos recursos. Já os surdos bilíngües estudam em classe especial, isto é, nas salas estudam somente crianças surdas (Harrison, Lodi \& Moura, 1997).

Aos surdos, tradicionalmente, foram atribuídos traços como pensamento concreto, elaboração conceitual rudimentar, baixa sociabilidade, rigidez, imaturidade emocional e outros no mesmo sentido. Essas características ora eram atribuídas às condições inerentes do surdo e ora às conseqüências da surdez (Góes, 1999). Segundo Corvera e Gonzalez (2000), é possível sustentar a premissa de perdas psicológicas para surdez, mas essa não seria inerente à surdez e sim gerada por conflitos sociais, ocupacionais, pedagógicos e familiares.

Nos estudos sobre o desenvolvimento cognitivo do surdo, há três marcos claramente definidos. Em 1923, as crianças surdas eram consideradas mentalmente inferiores às ouvintes, sob a justificativa de a surdez também afetar o cérebro, causando retardo mental. Mais tarde, em 1953, passou-se a considerar que surdos e ouvintes possuíam desempenho intelectual similar, mas os surdos eram mais ligados ao pensamento concreto e tinham menos raciocínios abstratos, dificultando a generalização do pensamento. Poucos anos depois, em 1960, afirmou-se que ambos os grupos eram iguais e que a ausência da fala não impediria o desenvolvimento intelectual do surdo (Moores, 1982).

Essas questões evidenciam a dificuldade para saber como os surdos se sentem e pensam, demonstrando, desse modo, a relevância de estudos que viabilizem avaliações psicológicas mais precisas sobre os aspectos da surdez. O objetivo da avaliação psicológica é avaliar os fenômenos psicológicos delimitados pelas condições teóricas, metodológicas e instrumentais de trabalho do psicólogo. O uso apropriado das técnicas de avaliação requer que esse profissional se atenha às inúmeras atividades e processos psicológicos envolvidos nelas, para o que é necessário haver diversificação das técnicas (Pasquali, 2001). Entretanto, quando são abordadas pessoas com deficiências, especialmente os surdos, há uma escassez no que se refere a instrumentos validados.

As técnicas projetivas de avaliação descrevem o indivíduo em termos de um esquema dinâmico de variáveis intercorrelacionadas, possibilitando conhecer aspectos estruturais quanto à dinâmica afetiva e as modalidades de funcionamento psíquico próprio de cada 
sujeito nas suas especificidades e nas suas articulações singulares (Anderson, 1967; Chabert, 2004).

Dentre os instrumentos projetivos, um que, por ser não-verbal, poderia ser usado com surdos é o Teste das Pirâmides Coloridas de Pfister (TPC) (Villemor-Amaral, 2005). Essa é uma técnica não-verbal, de rápida aplicação e sem característica escolar, minimizando o não-envolvimento com a tarefa e as limitações da impaciência e dificuldade de manutenção da atenção.

$\mathrm{O}$ TPC é um instrumento que fornece informações sobre "a dinâmica emocional tanto em relação aos afetos e defesas quanto em relação ao nível de maturidade da sua expressão no mundo das relações" (Villemor-Amaral, 2002, p. 51), isto é, permite verificar se o examinando reage aos estímulos emocionais com menor ou maior controle das funções cognitivas. Trata-se de um instrumento de fácil aplicação, no qual é solicitado que o testando preencha um esquema de pirâmide com quadrículos coloridos de diferentes tonalidades para que fiquem bonitas ao seu gosto (Villemor-Amaral, 2005).

Oliveira, Pasian e Jacquemim (2001) compararam grupos de idosos institucionalizados e não-institucionalizados e verificaram diferenças na produção de tapetes e estruturas. Costa (2004) objetivou verificar a correlação entre o aspecto formal do Pfister e o desempenho em provas de raciocínio da BPR-05. Após analisar os dados, constatou que aqueles que tinham pelo menos uma pirâmide com o aspecto formal estrutura tiveram melhor desempenho na BPR-05, demonstrando que é preciso um nível intelectual mais elevado ou maior capacidade de controle lógico para elaborar o aspecto formal estrutura no teste de Pfister. Em paralelo, os indivíduos que não usaram o aspecto formal tapete no TPC tiveram melhor desempenho na BPR-05 em relação aos que fizeram pelo menos 1 tapete. Esses achados corroboram Villemor Amaral (1978), quando disse que a produção de tapetes sugere perturbações emocionais de acentuada imaturidade em adultos ou crianças.

Alguns estudos recentes sobre o Pfister foram realizados por Villemor-Amaral, 2002, 2005; VillemorAmaral, Primi, Farah, Cardoso e Franco, 2003 e VillemorAmaral, Primi, Farah, Silva, Cardoso e Franco, 2004. Além disso, foram realizadas exaustivas buscas de referências sobre o uso do Pfister no contexto da deficiência auditiva. $\mathrm{Na}$ literatura internacional não houve achados e na nacional localizaram-se as dissertações de Souza (1986) e Kuhn (1990).

Souza (1986) objetivou verificar se o TPC permite caracterizar a personalidade de deficientes auditivos e examinar se há relação entre as variáveis: grau de perda auditiva, nível intelectual e desempenho no Pfister. Participaram 102 deficientes auditivos de 13 a 20 anos, que foram organizados em grupos de acordo com a perda Psico-USF, v. 12, n. 2, p. 135-144, jul./ dez. 2007 auditiva (limite entre os grupos de $80 \mathrm{~dB}$ ) e com a inteligência (limite entre os grupos de percentil 40). Os participantes foram comparados com o padrão teórico proposto por Villemor Amaral (1978). Nos resultados, evidenciou-se que os surdos diferenciaram-se dos ouvintes pela síndromes de cores vivas $\downarrow$, cores esbranquiçadas $\uparrow$, $\mathrm{A} z \downarrow, \mathrm{Vd} \downarrow$, ci $\uparrow$. Ademais, não foram verificadas diferenças significativas na comparação entre os dois grupos de surdos de acordo com a perda auditiva. Levando-se em conta o nível intelectual, observou-se algumas diferenças, tanto entre os grupos de surdos como entre cada um dos dois grupos, de maior ou menor perda auditiva, com o mesmo padrão teórico de Villemor Amaral (1978). É importante ressaltar que a pesquisa lidou com conceitos vagos e não estabeleceu parâmetros para afirmar seus resultados.

Kuhn (1990) objetivou caracterizar os aspectos afetivo-emocionais e intelectuais em um grupo de crianças com surdez neurossensorial profunda por meningite bacteriana sem outros comprometimentos orgânicos ou mentais. Para tal, avaliou 15 crianças surdas de 5 a 12 anos, sendo 10 meninos e 5 meninas, e um grupo controle de 20 crianças de mesma idade, sendo 9 meninos e 11 meninas, utilizando o TPC segundo a concepção Schaie e Heiss (1964) e o teste especial das matrizes progressivas de Raven (1951), citados por Kuhn (1990). O teste de Raven foi aplicado conforme sugestão do manual, o qual a autora chamou "sem pesquisa de atenção", e depois, a quem respondeu às questões incorretamente, foi informado que havia algum erro na resposta e dada nova chance de acerto, denominado procedimento "com pesquisa de atenção". As crianças surdas apresentaram $\mathrm{Vm} \uparrow, \mathrm{Ci} \downarrow, \operatorname{Pr} \downarrow$, síndrome acromática $\downarrow$, tapetes $\downarrow$, e formação em camada $\uparrow$ em relação ao grupo controle. Quanto aos resultados no teste de Raven, as surdas apresentaram um rebaixamento intelectual em relação aos ouvintes. No entanto, após as instruções "com pesquisa de atenção" obtiveram um desempenho intelectual significativamente melhor em relação à primeira situação. Esses achados levaram a pesquisadora a concluir que a pesquisa de atenção interfere significativamente no desempenho das crianças surdas.

Poucos estudos têm sido conduzidos no sentido de examinar o impacto dos diferentes métodos de comunicação e educação no ajustamento psicossocial de crianças surdas (Bailly, Dechoulydelenclave \& Lauwerier, 2003). Além disso, nos últimos anos as reflexões sobre a surdez ficaram restritas a postulados teóricos, sem possuir uma base empírica que consolide o que é falado.

Contudo, observou-se a necessidade de explorar os aspectos cognitivos e emocionais de surdos por meio de situações padronizadas e instrumentos válidos, garantindo maior veracidade científica. Este estudo objetivou verificar a sensibilidade da técnica para identificar diferenças de aspectos emocional e de estruturação congnitiva entre 
grupos contrastantes, assim como entre grupos de surdos conforme as políticas educacionais a que foram submetidos, bilingüismo, comunicação total ou oralismo.

\section{Método}

\section{Participantes}

Participaram do estudo 80 crianças com surdez bilateral, não usuárias de implante coclear. Destas, 29 eram bilíngües, 20 de comunicação total e 31 oralizadas. 50,6\% eram homens e 49,4\% eram mulheres, com idade entre $6 \mathrm{e}$ 12 anos (média 9,32 e mediana 10) e escolaridade entre pré e sexta série (média 3,65 e mediana 3,0). Os surdos foram pareados com 37 ouvintes, sendo 48,6\% homens e 51,4\% mulheres, com idade entre 7 e 12 anos (média e mediana 9,0), estudantes de pré a sétima série (média 3,58 e mediana 4).

Todos os participantes foram selecionados por meio de amostra não-aleatória por conveniência de diferentes instituições de cidades do interior paulista. $\mathrm{O}$ critério de inclusão no grupo de surdos foi ter perda auditiva neurossensorial bilateral congênita ou perinatal e, no grupo dos ouvintes, não ter histórico de estudos de recuperação escolar destinados a alunos com baixo rendimento escolar.

\section{Instrumentos}

Ficha de identificação: a ficha de identificação foi a mesma para todas as crianças, e as questões sobre a surdez não foram feitas aos ouvintes. A ficha foi organizada em duas partes: a primeira esclarecia dados da criança e a segunda, informações sobre a família.

Os questionamentos sobre as crianças foram sobre o sexo, idade, escolaridade, etiologia da surdez, tipo de comunicação utilizada, perda auditiva (melhor ouvido), tipo de educação surda à qual a criança foi exposta, tipo de escola que a criança freqüenta, tempo de aprendizado da língua utilizada pela criança e se a criança participa ou participou de algum processo psicoterapêutico.

Os dados da família requisitados foram se a família é legítima ou adotiva, o número de pessoas que a compõem, número de filhos, a ordem de nascimento dos filhos, renda familiar em faixas de salários mínimos, cidade na qual a família reside, se a procedência da família é rural ou urbana, a habitação da família, religião da família, se os pais são ouvintes ou deficiente auditivos, a escolaridade e profissão dos pais, aceitação dos pais frente à comunicação utilizada pelo filho e indícios de desagregação familiar.

Teste das Pirâmides Coloridas de Pfister (TPC): compreende um jogo com três cartões em papel bege com um esquema de pirâmide desenhado em cada um deles, um conjunto de quadrículos coloridos com 10 cores distribuídas em 24 tonalidades diferentes e a folha de aplicação (Villemor-Amaral, 2005).

A aplicação do teste consiste na execução de três pirâmides ao gosto do avaliando. Após o preenchimento da primeira pirâmide é solicitado que preencha outra e depois uma terceira pirâmide. Ao término da terceira pirâmide preenchida é realizado um inquérito para verificar a preferência do examinando pelas pirâmides (VillemorAmaral, 2005). Para análise dos indicadores, neste estudo, foram considerados os de aspecto formal, a freqüência das cores e síndromes cromáticas.

\section{Procedimentos}

Após aprovação pelo comitê de ética da Universidade São Francisco, pelos responsáveis nas instituições, pelos responsáveis pelas crianças e pelas próprias crianças, iniciaram-se os procedimentos de coleta de dados. Os instrumentos foram aplicados, em uma única sessão individual, primeiro a ficha de identificação e depois o TPC. As instruções foram realizadas de acordo com a língua da criança, ou seja, utilizando-se LIBRAS na comunicação com as crianças bilíngües, fala concomitante aos sinais com as de comunicação total e fala com as crianças oralizadas e ouvintes. Para as análises estatísticas, os dados das crianças foram pareados quanto ao gênero, idade e nível socioeconômico da família.

No inquérito do Pfister, as crianças surdas de comunicação total e oral, quando questionadas sobre por que haviam escolhido determinada pirâmide como a mais bonita, mudavam de opinião e apontavam para outra pirâmide com expressão facial de dúvida. A pesquisadora teve a impressão que as crianças buscavam uma resposta considerada certa, por isso, nesses casos, adotou-se como padrão dizer "não há uma resposta certa ou errada. Você pode escolher a pirâmide que considera mais bonita para você e me dizer o que nela fez com que você a escolhesse". Nesse caso, algumas crianças justificaram a escolha da primeira pirâmide e outras apenas diziam não saber.

\section{Resultados e discussão}

A relevância dos estudos de evidências de validade às técnicas projetivas foi destacada por Anderson (1967); Chabert (2004) e Pasquali (2001). Esses autores alertaram sobre a importância dessas pesquisas serem cuidadosamente planejadas.

Para análise dos dados, primeiramente foram realizadas as estatísticas descritivas referentes à ficha de identificação dos sujeitos para cada um dos quatro grupos: ouvintes, surdos oralizados, surdos de comunicação total e surdos bilíngües. Em seguida, foram feitas as análises para verificar as comparações entre surdos e ouvintes e, depois, entre os três sistemas educacionais dos grupos de surdos. 
Essa seqüência de procedimentos estatísticos foi repetida com os indicadores do teste de Pfister.

Ao considerar a ficha de identificação, buscou-se comparar as médias, pela prova t de Student considerando nível de significância de $\mathrm{p}=0,05$, entre ouvintes $(\mathrm{n}=37$ ) e surdos $(\mathrm{n}=81)$, e verificar se havia eventuais diferenças em todos os itens da ficha de identificação, pois essas informações poderiam interferir nos dados comparativos posteriores. A diferença de média estatisticamente significativa na comparação dos grupos entre surdos e ouvintes é apresentada na Tabela 1. Os demais dados mencionados na ficha de identificação não são citados na Tabela 1 por não terem apresentado diferenças significativas.

Tabela 1 - Diferença de média na comparação entre surdos e ouvintes

\begin{tabular}{lccc}
\hline & $\mathrm{t}$ & Grau de liberdade & Sig. \\
\hline Participação em processo psicoterapêutico & 10,226 & 116 & 0,000 \\
Cidade em que a família reside & 2,896 & 116 & 0,005 \\
Habitação da família & $-2,228$ & 115 & 0,028 \\
Profissão do pai & 2,221 & 102 & 0,029 \\
Morte de um dos pais & 2,401 & 108 & 0,018 \\
\hline
\end{tabular}

As diferenças nas variáveis "participação em processo psicoterapêutico" e "cidade em que a família reside" são conseqüências das condições institucionais onde foram coletados os dados, pois todas as instituições são localizadas em cidades diferentes, e uma delas fornece atendimento psicoterapêutico a todos seus usuários. Além disso, na seleção dos ouvintes houve uma preocupação em controlar para que estes não tivessem histórico de acompanhamento ou busca de tratamento psicoterapêutico ou psiquiátrico. Já no que se refere à habitação da família, os surdos dessa amostra tinham melhores condições de habitação, 56,2\% deles com casa própria. 43,2\% dos ouvintes estavam na mesma situação.

Destaca-se que os indicadores profissão do pai e morte de um dos pais foram significativamente diferentes e podem ser variáveis que interferiram nos resultados obtidos. Entretanto, não era o objetivo desta pesquisa investigar o grau de influência desses indicadores de desagregação familiar no desenvolvimento emocional e cognitivo do surdo. A profissão dos pais teve uma distribuição bastante heterogênea, apesar de 16\% dos pais de ouvintes e $26 \%$ dos de surdos não declararem a profissão. Das profissões declaradas, as mais freqüentes foram comerciante e ajudante geral, sendo respectivamente $10,8 \%$ e $9,7 \%$ no caso dos ouvintes e $12,4 \%$ e $15,5 \%$ no dos surdos. Em relação ao item morte de um dos pais, foi mais freqüente nas crianças surdas $(35 \%) \mathrm{em}$ relação às ouvintes $(0 \%)$.

Para verificar a diferença de médias entre os três grupos de surdos, oralizados $(n=31)$, comunicação total $(n=20)$ e bilíngües $(n=29)$, utilizou-se a prova chi-square em todas as variáveis referentes aos dados da criança e de sua família, conforme detalhado na Tabela 2.

Tabela 2 - Diferenças entre os grupos de surdos

\begin{tabular}{lccc}
\hline Variável & Chi-square & Grau de liberdade & Sig. \\
\hline Escolaridade & 20,621 & 12 & 0,056 \\
Etiologia & 42,982 & 24 & 0,010 \\
Tipo de comunicação utilizada & 162,000 & 4 & 0,000 \\
Perda auditiva no melhor ouvido & 74,439 & 6 & 0,000 \\
Tipo de escola que a criança freqüenta & 81,000 & 4 & 0,000 \\
Forma de comunicação com a família & 117,532 & 6 & 0,000 \\
Aceitação da criança frente ao aparelho auditivo & 18,344 & 6 & 0,005 \\
Participação em processo psicoterapêutico & 37,148 & 4 & 0,000 \\
Número de pessoas na família & 24,124 & 14 & 0,044 \\
Ordem de nascimento do fillho & 20,411 & 10 & 0,026 \\
Cidade em que a família reside & 87,502 & 24 & 0,000 \\
Doença mental na família & 9,385 & 2 & 0,009 \\
Doença física na família & 6,025 & 2 & 0,049 \\
Alcoolismo & 12,114 & 2 & 0,002 \\
\hline
\end{tabular}


Dentre os aspectos da Tabela 2, um que pode gerar diferenças entre os grupos e que foi marginalmente significativo, do ponto de vista estatístico, é a escolaridade. As diferenças em relação à escolaridade são apresentadas na Tabela 3.

Tabela 3 - Freqüência do tipo de comunicação dos surdos em relação à escolaridade

\begin{tabular}{|c|c|c|c|c|}
\hline \multirow{2}{*}{ Escolaridade } & \multicolumn{3}{|c|}{ Tipo de comunicação utilizada pelos surdos } & \multirow[t]{2}{*}{ Total } \\
\hline & Língua de sinais & Comunicação total & Oral & \\
\hline Pré & 7 & 2 & 2 & 11 \\
\hline Primeira série & 5 & 5 & 5 & 15 \\
\hline Segunda série & 9 & 4 & 3 & 16 \\
\hline Terceira série & 4 & 2 & 7 & 13 \\
\hline Quarta série & 4 & 4 & 4 & 12 \\
\hline Quinta série & 0 & 1 & 7 & 8 \\
\hline Sexta série & 0 & 2 & 3 & 5 \\
\hline Total & 29 & 20 & 31 & 80 \\
\hline
\end{tabular}

A maior concentração de crianças bilíngües em relação à escolaridade está do pré à segunda série, diferindo do grupo de crianças oralizadas, concentradas da terceira à quinta série. Este dado deve ser considerado, principalmente, no que se refere aos aspectos cognitivos no teste de Pfister, mas na literatura consultada sobre o teste não há referência a estudos normativos para crianças (Costa, 2004; Oliveira, Pasian \& Jacquemim, 2001; Villemor Amaral, 1978; VillemorAmaral, 2002, 2005; Villemor-Amaral e cols., 2003, 2004). Aponta-se que as eventuais diferenças que surgiram entre os indicadores do teste devem ser observadas de modo cauteloso, pois não se sabe se acontecem em função dos modelos educacionais, ou por conta da diferença de escolaridade.

As diferenças na comunicação utilizada, no tipo de escola que a criança freqüenta e na forma de comunicação com as famílias é justificada pela ideologia do modelo educacional em que as crianças estão inseridas. Harrison, Lodi e Moura (1997) discutem em que medida a escolha de uma política educacional para o surdo pode influenciar nesses fatores. Destaca-se que, tal como menciona a literatura, os responsáveis pelas instituições informaram o tipo de escola que indicam aos familiares dos surdos, por conta dos princípios de cada modelo. Assim, as instituições oralizadora e comunicação total recomendam escola comum e a instituição bilíngüe indica escola especial. Já a participação em processo psicoterapêutico e cidade em que a criança reside tiveram diferenças significativas por conta da localização da instituição e do tipo de atendimentos disponibilizados pelas mesmas, conforme já comentado ao se referir sobre as diferenças entre surdos e ouvintes.

Após a análise dos dados de identificação, buscaram-se diferenças entre os grupos em relação ao teste de Pfister. Foi feita a comparação entre os indicadores emocionais estudados, isto é, as variáveis de porcentagem da cor e porcentagem das síndromes cromáticas do teste de Pfister. Primeiro realizou-se o t de Student na comparação da freqüência de cores e síndrome cromática entre ouvintes e surdos.

A porcentagem da cor violeta foi a única variável estatisticamente significativa $(\mathrm{t}=2,238, \mathrm{p}=0,027)$. A média da porcentagem de uso do violeta pelos surdos foi 15,58, enquanto a média da porcentagem pelos ouvintes foi 11,64, ou seja, os surdos apresentaram aumento na freqüência de uso da cor violeta em relação aos ouvintes. Esse dado não havia sido obtido nos estudos anteriores de Kuhn (1990) e Souza (1986).

Ao violeta são atribuídas tensão e ansiedade (Villemor Amaral, 1978; Villemor-Amaral, 2005). Desse modo os dados indicariam que o grupo de surdos desta amostra é mais ansioso que os ouvintes. Sole (2003) mencionou que surdos seriam mais ansiosos que ouvintes e justificou essa ansiedade pela tensão afetiva, que não é aliviada na forma de palavras. A impulsividade seria efeito da falta de metabolização psíquica dessas tensões que não se podem descarregar na motricidade. Ademais, a presença de ansiedade em surdos poderia ser justificada pelas limitações lingüísticas vivenciadas por eles na primeira infância, tal como mencionaram Capovilla (1997), Capovilla e Raphael (2004), Torres (2005) e Vygotsky (1989).

Em seguida foi usado ANOVA na comparação da freqüência de cores e síndromes cromáticas entre os grupos de surdos, não havendo diferenças significativas nos indicadores mencionados do Pfister.

Desse modo, neste estudo não foi possível identificar dados que possibilitassem confirmar ou refutar os estudos obtidos no American Annal of Deaf (2006); Bailly, Dechoulydelenclave \& Lauwerier (2003); Corvera e Gonzalez (2000); Ferreira Brito (1993); Góes (1999); 
Hindley (1997); Kyle (1999); Lacerda (1998); Marchesi (1995) e Skliar (1998).

Para verificar diferenças nos aspectos cognitivos, usando o teste das Pirâmides, considerou-se como variável o aspecto formal. Para tal, foi usado chi-square de Spearman e os resultados da comparação, surdos e ouvintes, são apresentados na Tabela 4.

Tabela 4 - Freqüência dos indicadores significativos entre surdos e ouvintes

\begin{tabular}{|c|c|c|c|}
\hline Variável & Chi-square & Grau de liberdade & Sig. \\
\hline Presença de tapete puro & 7,078 & 1 & 0,008 \\
\hline Presença de tapete furado ou desequilibrado & 2,470 & 1 & 0,116 \\
\hline Presença de tapete com inicio de ordem & 5,393 & 1 & 0,020 \\
\hline Presença de formação em camada multicromática & 0,002 & 1 & 0,965 \\
\hline Presença de formação em camada monotonal & 0,782 & 1 & 0,376 \\
\hline Presença de formação simétrica & 3,357 & 1 & 0,067 \\
\hline Presença de estrutura simétrica & 15,144 & 1 & 0,000 \\
\hline Pres. formação em camada com tendência a estrutura & 1,866 & 1 & 0,172 \\
\hline Presença de estrutura em manto & 1,271 & 1 & 0,260 \\
\hline Presença de formação em ladrilho & 8,723 & 1 & 0,003 \\
\hline
\end{tabular}

$\mathrm{Na}$ comparação dos aspectos formais, as diferenças significativas do ponto de vista estatístico, são:

- Surdos apresentaram tapete puro $(p=0,008)$ e tapete com início de ordem $(\mathrm{p}=0,020)$ em uma das três pirâmides com maior freqüência que os ouvintes;

- Os ouvintes apresentaram maior freqüência de estrutura simétrica $(p=0,000)$ e presença de formação em ladrilho $(p=0,003)$ em uma das três pirâmides que os surdos.

Desse modo, evidencia-se que os surdos apresentaram freqüência maior de pelo menos um aspecto formal tapete em relação aos ouvintes. E os ouvintes apresentaram freqüência maior de formação e estrutura que os surdos.
Costa (2004), ao correlacionar o Pfister com a BPR-5, verificou que a presença de um tapete numa das três pirâmides estaria associado a um nível intelectual inferior ao daquelas pessoas que não fazem tapete. Seguindo o mesmo raciocínio, a presença de estrutura indicaria nível intelectual mais sofisticado. Neste estudo, os indicadores apontam para um nível de estruturação cognitiva diferente entre ouvintes e surdos. Nas pesquisas sobre o desenvolvimento cognitivo de surdos, verificou-se que as discussões sobre um possível déficit nas crianças surdas são de longa data (Moores, 1982), ora afirmando a defasagem ora negando-a.

Em seguida, foram comparados os aspectos cognitivos do Pfister entre os grupos de surdos. Os resultados estão apresentados na Tabela 5.

Tabela 5 - Distribuição da freqüência dos aspectos formais entre os grupos de surdos

\begin{tabular}{lccc}
\hline \multicolumn{1}{c}{ Variável } & Chi-square & Grau de liberdade & Sig. \\
\hline Presença de tapete puro & 15,338 & 2 & 0,000 \\
Presença de tapete furado ou desequilibrado & 25,095 & 2 & 0,000 \\
Presença de tapete com início de ordem & 26,836 & 2 & 0,000 \\
Presença de formação em camada multicromática & 10,096 & 2 & 0,006 \\
Presença de formação em camada monotonal & 17,958 & 2 & 0,000 \\
Presença de formação simétrica & 13,665 & 2 & 0,001 \\
Presença de estrutura simétrica & 0,343 & 2 & 0,843 \\
Pres. formação em camada com tendência a estrutura & 6,403 & 2 & 0,041 \\
Presença de estrutura em manto & 6,403 & 2 & 0,041 \\
Presença de estrutura simétrica & 11,380 & 2 & 0,003 \\
\hline
\end{tabular}

Ao analisar a Tabela 5 , verifica-se que a maioria dos indicadores foi significativamente diferente e que um número maior de surdos oralizados apresentou pelo menos um aspecto formal estrutura no conjunto de três pirâmides. Os surdos de comunicação total foram o grupo intermediário em relação à presença de pelo menos uma 
pirâmide com aspecto formal estrutura, enquanto os bilíngües foram os que menos apresentaram pirâmides com estrutura.

Somando esses dados, observou-se que um número menor de surdos oralizados apresenta tapetes em pelo menos uma pirâmide. Novamente o grupo de comunicação total esteve num nível intermediário e, dessa vez, um número maior de surdos bilíngües apresentou pelo menos um aspecto formal tapete em uma pirâmide do teste.

Conforme já mencionado, Costa (2004) verificou que a presença de estrutura em uma pirâmide estaria atrelada a um nível intelectual mais elaborado. Em oposição, a presença de tapete em uma pirâmide estaria associada a um nível intelectual menos sofisticado. Deste modo, os dados mencionados acima seriam indicativos de que, nesta amostra, os surdos oralizados teriam um nível intelectual mais estruturado que os de comunicação total, que teriam um nível intelectual acima dos bilíngües. Conforme já mencionado nas tabelas 2 e 3, há uma diferença na escolaridade entre os grupos de surdos, portanto, essas diferenças não se deram necessariamente em função do modelo educacional em que estão inseridos, mas podem ter ocorrido em virtude das diferenças de escolaridade.

Além disso, de acordo com o histórico da surdez, o bilingüismo foi aceito como meio de eliminar as limitações escolares impostas pela comunicação total, que já teria surgido como maneira de superar os déficits que o modelo oralizador não supriu (Capovilla,1997; Capovilla \& Raphael, 2004; Goldfeld, 1997; Lopes Filho, 1997; Magalhães, 2006; Perlin, 1998; Sá, 1999). Desse modo, é preciso ter um olhar atento sobre esses dados e sugere-se maior rigor em relação à escolaridade das crianças em estudos posteriores.

\section{Considerações finais}

Os resultados do Pfister, neste trabalho, evidenciam traços de ansiedade em surdos quando comparados com ouvintes. Os surdos apresentam boa estruturação cognitiva, embora neste estudo os ouvintes tenham demonstrado uma estrutura mais sofisticada que a deles. Essa diferença também foi verificada entre os surdos, de modo que os oralizados, neste estudo, teriam uma estrutura cognitiva mais sofisticada que os de comunicação total, que teriam uma organização cognitiva mais elaborada que os bilíngües.

Ao considerar esses resultados é preciso atentarse aos seus significados. A presença de ansiedade é encontrada em diferentes quadros psicopatológicos e é um sinal de alerta muito importante. No trabalho com os surdos é preciso que se considere essa característica tomando-se os devidos cuidados para não considerar a ansiedade como cristalizada no grupo. Além disso, o fato de indicarem boa estruturação cognitiva é um fator positivo até mesmo para lidar com esse alerta.

De qualquer modo, esses resultados suscitam novas indagações. Essas diferenças na estruturação cognitiva e ansiedade seriam originadas em que momento? E por quê? Elas seriam intrínsecas à surdez ou se dariam por vivências ao longo da vida? Ou seriam, ainda, conseqüência das dificuldades de comunicação ao tentar estabelecer as redes sociais e lingüísticas desde o início da vida? Qual a influência de fatores genéticos, familiares e etiológicos nesses dados? São questões merecedoras de estudos e reflexões.

Ainda falando sobre a utilização do teste de Pfister para surdos, vale destacar que, neste estudo, não foi feita a análise de fórmula cromática, mas que seria interessante se pesquisas futuras considerassem esse indicador. A fórmula cromática leva em conta a amplitude, isto é, abertura aos estímulos, e o grau de estabilidade nas escolhas.

Neste estudo faltou realizar análises entre juízes para codificação independente, as quais permitiriam um estudo de fidedignidade do instrumento. Os estudos de fidedignidade têm sido bastante relevantes e permitem afirmar a confiabilidade do instrumento, sendo muito importantes para pesquisas realizadas com técnicas projetivas. Ademais, nota-se que os indicadores do teste de Pfister foram bastante restritos, pois se consideraram apenas aspecto formal, cores e síndromes cromáticas. Há outros indicadores que poderiam ter sido explorados $\mathrm{e}$ podem vir a ser alvo de pesquisas futuras. No entanto, os resultados obtidos contribuem para evidências de validade do TPC no contexto da surdez, destacando-se alguns pontos em que o TPC pode contribuir para melhoria da compreensão da dinâmica emocional e organização cognitiva de surdos.

\section{Referências}

American Annal of Deaf. Obtido em 5 de maio de 2006 do World Wide Web: http://gupress.gallaudet.edu/annals/.

Anderson, H. H. (1967). Comportamento humano e desenvolvimento da personalidade. Em H. H. Anderson \& G. L. Anderson. Técnicas projetivas de diagnóstico psicológico (E. Bennett, trad.). São Paulo: Mestre Jou.

Bailly, D., Dechoulydelenclave, M. B. \& Lauwerier, L. (2003). Hearing impairment and psychopathological disorders in children and adolescents: Review of the recent literature. Encephale, 29(4), 329-337.

Capovilla, F. C. (1997). Filosofias educacionais em surdez: oralismo, comunicação total e bilingüismo.

Psico-USF, v. 12, n. 2, p. 135-144, jul./ dez. 2007 
Ciência cognitiva: teoria, pesquisa e aplicação, 1(2), 561588.

Capovilla, F. C. \& Raphael, W. D. (2004). Enciclopédia da lingua de sinais brasileira: o mundo do surdo em libras. São Paulo: [Fundação] Vitae, FAPESP, Editora da Universidade de São Paulo, Imprensa Oficial do Estado de São Paulo.

Chabert, C. (2004). Psicanálise e métodos projetivos. São Paulo: Vetor.

Corvera, J. \& Gonzalez, F. (2000). The psychodynamics of deafness. Gac. Med. Mex., 136(2),139-51.

Costa, O. R. S. (2004). Um estudo correlacional das pirâmides de Pfister e a BPR-5. Dissertação de Mestrado. Itatiba, SP: Universidade São Francisco Pós-graduação Stricto Sensu em Psicologia.

Ferreira-Brito, L. (1993). Integração social \& surdez. Rio de Janeiro: Babel.

Góes, M. M. R. de (1999). A linguagem, surdez e educação. ( $2^{\mathrm{a}}$ ed.). Campinas, SP: Editores Associados.

Goldfeld, M. (1997). A criança surda: linguagem e cognição numa perspectiva sócio-interacionista. São Paulo: Plexus.

Harrison, K. M. P., Lodi, A. C. B. \& Moura, M. C. (1997). Escolas e escolhas: o processo educacional do surdo. Em O. C. Lopes Filho (Org.). Tratado de fonoaudiologia (pp. 359-400). São Paulo: Roca.

Hindley, P. (1997). Psychiatric aspects of hearing impairments. Journal Child Psychology Psychiatry, 38(1), 101-17.

Kuhn, A. M. B. (1990). Avaliação psicológica dos aspectos afetivo-emocionais e intelectuais em uma população de crianças com surdez neurosensorial profunda. Tese de Doutorado. São Paulo, SP: Universidade Federal de São Paulo - Escola Paulista de Medicina.

Kyle, J. (1999). O ambiente bilíngüe: alguns comentários sobre o desenvolvimento do bilingüismo para surdos. Em C. Skliar. Atualidade da educação bilíngüe para surdos. (vol. I). Porto Alegre: Mediação.

Lacerda, C. B. F. de (1998). Um pouco da história das diferentes abordagens na educação dos surdos Caderno CEDES, 19(46), 68-80.

Lopes Filho, O. C. (1997). Deficiência auditiva. Em O. C. Lopes Filho (Org.). Tratado de fonoaudiologia (pp. 3-24). São Paulo: Roca.

Magalhães, V. (2006). Obtido em 10 de janeiro de 2006 do World Wide Web: http://www.surdosce.org.br/subsidios/artigo2.htm.
Marchesi, A. (1995). Comunicação, linguagem e pensamento das crianças surdas. Em C. Coll, J. Palacios \& A. Marchesi. Desenvolvimento psicológico e educação: necessidades educativas especiais e aprendizagem escolar (M. A. G. Domingues, trad). Porto Alegre: Artes Médicas.

Moores, D. F. (1982). Educating the deaf: psychology, principles and practices ( $2^{\mathrm{a}}$ ed.). Boston: Houghton Mifflin.

Oliveira, E. A., Pasian, S. R. e Jacquemim, A. (2001). A vivência afetiva dos idosos. Psicologia: Ciência e Profissão, 21(1), 68-83.

Pasquali, L. (2001). Técnicas de exame psicológico-TEP: manual. São Paulo: Casa do Psicólogo.

Perlin, G. T. T. (1998). Histórias de vida surda: identidade em questão. Dissertação de Mestrado. Porto Alegre, RS: Universidade Federal do Rio Grande do Sul Faculdade de Educação.

Sá, N. R. L. (1999). Educação de surdos: a caminho do bilingüismo. Niterói: Eduff.

Skliar, C. (1998). A surdez: um olhar sobre as diferenças. Porto Alegre: Mediação.

Sole, M. C. P. (2003). O sujeito surdo e a psicanálise; uma outra via de escuta. Tese de Doutorado. São Paulo, SP: Pontifícia Universidade Católica de São Paulo.

Souza, R. M. (1986). Contribuições do estudo da personalidade de adolescentes surdos através do TPC de Max Pfister. Dissertação de Mestrado. Campinas, SP: Pontifícia Universidade Católica de Campinas.

Torres, S. (2005). Deficiência auditiva infantil: psicopatologia e tratamento. Em V. E. Caballo \& M. A. Simon. Manual de psicologia clinica infantil e do adolescente: transtornos específicos (S. M. Dolinsky, trad.). São Paulo: Santos.

Villemor Amaral, F. (1978). Pirâmides coloridas de Pfister. (2 ${ }^{\mathrm{a}}$ ed.). Rio e Janeiro: CEPA.

Villemor-Amaral, A. E. (2002). Novas contribuições ao Teste das Pirâmides Coloridas de Pfister. Em R. Primi (Org.). Temas em avaliação psicológica (pp. 5055). Laboratório de Avaliação Psicológica e Educacional, Pós-Graduação Stricto Sensu em Psicologia. Universidade São Francisco. IBAP (Instituto Brasileiro de Avaliação Psicológica).

Villemor-Amaral, A. E. (2005). O Teste das Pirâmides Coloridas de Pfister. São Paulo: CETEP.

Villemor-Amaral, A. E., Primi, R., Farah, F. H. Z., Cardoso, L. M. \& Franco, R. R. C. (2003). Revisão das expectativas no Pfister para uma amostra 
normativa. Avaliação Psicológica, 2(2), 185-188.

Villemor-Amaral, A. E., Primi, R., Farah, F. H. Z., Silva, S. M. da, Cardoso, L. M. \& Franco, R. R. C. (2004). A depressão no Teste das Pirâmides Coloridas de Pfister. Paidéia: Cadernos de Psicologia e Educação, 14(28), 169-179.
Vygotsky, L. S. (1989). A formação social da mente. São Paulo: Martins Fontes (Originalmente publicado em 1934).

Recebido em junho de 2007 Reformulado em setembro de 2007 Aprovado em outubro de 2007

Sobre os autores:

Lucila Moraes Cardoso é psicóloga, mestre em Psicologia pela Universidade São Francisco.

Cláudio Garcia Capitão é psicólogo, professor da Graduação e do Programa de Pós-Graduação Stricto Sensu em Psicologia da Universidade São Francisco. 